\title{
Interplays between Enterovirus A71 and the innate immune system
}

\author{
Kuan-Ru Chen ${ }^{1}$ and Pin Ling ${ }^{1,2,3^{*}}$
}

\begin{abstract}
Enterovirus A71 (EV-A71) is a growing threat to public health, particularly in the Asia-Pacific region. EV-A71 infection is most prevalent in infants and children and causes a wide spectrum of clinical complications, including hand-footand-mouth disease (HFMD), pulmonary and neurological disorders. The pathogenesis of EV-A71 infection is poorly understood at present. It is likely that viral factors and host immunity, and their interplay, affect the pathogenesis and outcome of EV-A71 infection. The mammalian innate immune system forms the first layer of defense against viral infections and triggers activation of adaptive immunity leading to full protection. In this review, we discuss recent advances in our understanding of the interaction between EV-A71 and the innate immune system. We discuss the role of pattern-recognition receptors (PRRs), including Toll-like receptors (TLRs), RIG-I-like receptors (RLRs), and inflammasomes, in the detection of EV-A71 infection and induction of antiviral immunity. As a counteraction, EV-A71 viral proteins target multiple innate immune pathways to facilitate viral replication in host cells. These novel insights at the virus-host interphase may support the future development of vaccines and therapeutics against EV-A71 infection.
\end{abstract}

Keywords: Enterovirus A71 (EV-A71), EV-A71 3C protease, EV-A71 2A protease, EV-A71 pathogenesis, TLRs, RLRs, NLRs

\section{Introduction}

Enterovirus A71 (EV-A71) belongs to the Enterovirus genus in the Picornaviridae family and is a non-enveloped virus containing a positive single-stranded RNA (ssRNA) [1]. It was first identified in 1969 from children with the central nerve system-related complications [2]. EV-A71 infection causes outbreaks of hand-foot-and-mouth disease (HFMD) in infants and young children [3]. Severe cases are frequently associated with neurological complications like aseptic meningitis, acute flaccid paralysis, and encephalitis [3-5]. Clinical results indicated that deregulated inflammatory responses like cytokine storm might play a critical role in the EV-A71 pathogenesis [3]. At present, effective treatments and vaccines against EV-A71 are still warranted. Three formalin-inactivated EV-A71 vaccines for clinical treatment have been licensed in China [6-10]. In Taiwan, an inactivated EV-A71 vaccine has been developed and completed phase I and phase II studies [11, 12].

\footnotetext{
* Correspondence: lingpin@mail.ncku.edu.tw

'Department of Microbiology and Immunology, College of Medicine,

National Cheng Kung Univeristy, Tainan, Taiwan

${ }^{2}$ Institute of Basic Medical Sciences, College of Medicine, National Cheng

Kung Universiy, Tainan, Taiwan

Full list of author information is available at the end of the article
}

Additionally, human intravenous immunoglobulin (IVIG) is used for the treatment of EV-A71-associated brainstem encephalitis [13], but studies indicated that the antibodydependent enhancement phenomenon is observed in EV71-infected patients [14-16].

EV-A71 has been shown to use scavenger receptor B2 (SCARB2) and P-selectin glycoprotein ligand-1 (PSGL-1) as entry receptors to establish infection in mammalian cells $[17,18]$. Other molecules, including sialylated glycans [19], nucleolin [20], heparan sulfate glycosaminoglycan [21], and tryptophanyl-tRNA synthetase [22], are also shown to implicate in the infection of EV-A71 into mammalian cells. During EV-A71 infection, the positive sense ssRNA of EV-A71 encodes a large polyprotein, which in turn undergoes a series of cleavage processes to generate four structural viral proteins 1 to 4 (VP1-VP4) and seven nonstructural proteins (2A-2C and 3A-3D) [23]. EV-A71 2A protease cleaves between P1 and P2, whereas EV-A71 3C protease cleaves between P2 and P3 [23]. In addition to processing viral proteins, $2 \mathrm{~A}$ and $3 \mathrm{C}$ are shown to target several host PRRs and innate immune regulators during infection. EV71 3D protein is transcribed as an RNA-dependent RNA

(c) The Author(s). 2019 Open Access This article is distributed under the terms of the Creative Commons Attribution 4.0 International License (http://creativecommons.org/licenses/by/4.0/), which permits unrestricted use, distribution, and reproduction in any medium, provided you give appropriate credit to the original author(s) and the source, provide a link to the Creative Commons license, and indicate if changes were made. The Creative Commons Public Domain Dedication waiver (http://creativecommons.org/publicdomain/zero/1.0/) applies to the data made available in this article, unless otherwise stated. 
polymerase (RDRP) to synthesize a complement negative strand in the cytoplasm [23].

The innate immune system elicits the first line of host defenses against pathogen infection meanwhile it links to the activation and programming of adaptive immune responses, leading to the full spectrum of immune protection. The host innate immune system detects invading pathogens by pattern-recognition receptors (PRRs) through recognizing conserved microbial components known as pathogenassociated molecular patterns (PAMPs) [24]. Several PRR families are existed in the mammalian innate immune system, including Toll-like receptors (TLRs), RIG-I-like receptors (RLRs), NOD-like receptors (NLRs), C-type lectin receptors [24-26], and cytosolic DNA sensors (DDX41, IFI16, and cGAS) $[25,27,28]$. Cytosolic innate immune regulators help to relay the PRR signals to the major downstream pathways, including NF-kB, MAPK, and/or IRF3/7, which in turn induce the production of inflammatory cytokines and/or type I interferons (IFNs) for mounting innate immune responses.

During viral infection, viral components, like viral proteins and viral nucleic acids, serve as PAMPs to be detected by PRRs to trigger antiviral innate immune responses. Several PRRs, such as endosomal TLRs (TLR3, TLR7/8, and TLR9), cytosolic RLRs (RIG-I and MDA5) and DNA sensors (DDX41, IFI16, and cGAS), detect viral nucleic acids to trigger downstream signaling pathways, resulting in the induction of type I IFNs and inflammatory cytokines [29, 30]. Type I IFNs are key for inducing effective antiviral immunity [31]. Type I IFNs serve two major functions at the early phase of viral infection. First, they activate hundreds of IFNstimulated genes (ISGs) via the JAK-STAT pathways for mounting the antiviral state in virus-infected cells and neighboring cells [32, 33]. Second, they help dendritic cell maturation to enhance antigen presentation to $\mathrm{T}$ cells, then leading to viral antigen-specific adaptive immune responses [34]. Recent studies indicated that Type III IFNs can be produced earlier than type I IFNs by epithelial cells to controls viral infection at epithelial barriers [35]. It is also known that viruses develop sophisticated strategies to subvert antiviral innate immunity through targeting the PRR pathways and the JAK-STAT pathways $[36,37]$. Further studies on decoding the complicated interactions between viruses and the mammalian innate immune system may cast insights toward the development of novel antiviral treatments. Here we review the current understanding of the mechanisms by which the mammalian innate immune system detects and responds to EV-A71 infection. In addition, we highlight the emerging roles of EV-A71 viral proteins in counteracting host innate immune pathways to promote viral propagation.

\section{A1, interplays between EV-A71 and the toll-like receptor pathways}

The TLR family includes ten members in the human genome, and they can be categorized into two subgroups by their cellular distributions: cell surface TLRs and endosomal TLRs [31]. Cell surface TLRs are responsible for detecting microbial lipids, lipopeptides, and peptidoglycans from extracellular pathogens. Endosomal TLRs are located in the endolysosomal compartments to detect microbial nucleic acids from the endocytic, phagocytic, and autophagic pathways during pathogen infection. MyD88 is a key adaptor mediating downstream signaling in all TLR pathways except TLR3 $[38,39]$. Trif is another adaptor critical for the endosomal TLR3 pathway and the endocytic branch of the TLR4 pathway [38, 39]. By far, endosomal TLRs have been well described to be involved in priming type I IFN-mediated antiviral responses against virus infection. We highlight the roles of TLRs in innate immune recognition of and defense against EV-A71 infection. The interplays between TLRs and EV-A71 infection are illustrated in Fig. 1 and Table 1.

A recent study revealed that TLR3 is a key sensor to detect viral dsRNA during EV-A71 infection, and subsequently to trigger downstream signaling to type I IFN induction and antiviral responses [41]. This TLR3-mediated detection of EV-A71 is established in TLR3-transfected HEK293 cells, primary macrophages and dendritic cells [41]. Of note, TLR3 was also shown to be a target of EVA71 infection [41]. This notion will be discussed further in section A2 below. Another study also indicated that EVA71 replication is increased in a human colon cancer cell line HT-29 after Trif is depleted by siRNA. Studies using TLR3-deficient mice have also revealed that TLR3 plays a critical role in defending against several enterovirus infections, such as Coxsackievirus A16, Coxsackievirus B3, Coxsackievirus B4, EV-A71, and Poliovirus [42, 52-54]. Notably, Zhu et al. found that invariant natural killer $\mathrm{T}$ (iNKT) cells are a key immune cell population induced in young mice after EV-A71 infection, leading to the protection of mice from EV71 infection [42]. Their findings further indicated that in vivo activation of iNKT cells after EV-A71 infection relies on TLR3 signaling in macrophages [42]. Furthermore, susceptibility to EV-A71 infection was shown to be age-dependent in mouse models $[42,55]$. Of interest, genetic association studies from patients suggest that TLR3 gene polymorphisms are associated with the severity of EV-A71 infection in Chinese children [56, 57].

TLR7 is highly expressed in plasmacytoid DCs (pDCs), which produce a large amount of type I IFNs during virus infection. TLR7 detects ssRNA in endosomes and then activates the MyD88-dependent pathway through IKK $\alpha$ and IRF7 to IFN- $\alpha$ production [24, 58]. Notably, TLR7 has been shown to recognize the GU-rich and AU-rich ssRNA species from vesicular stomatitis virus (VSV), flaviviruses, Coxsackie B virus, and influenza A virus [52]. Recent studies have revealed the emerging roles of TLR7 in response to EV-A71 infection. Luo et al. demonstrated that EV-A71 infection induces the 


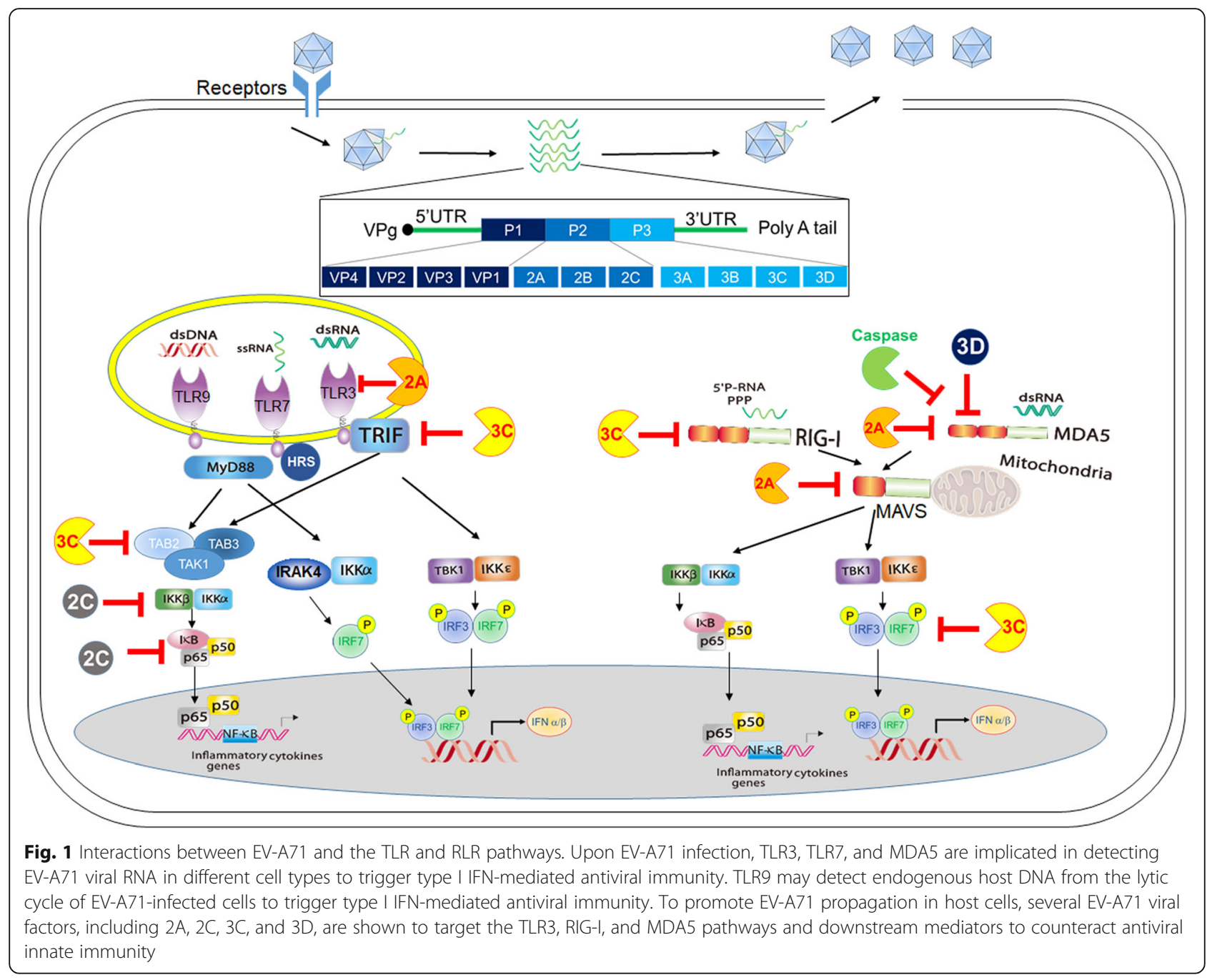

Table 1 PRRs detect EV-A71 infection

\begin{tabular}{llll}
\hline PRRs & Cell lines and types & PAMPs and sensing mechanisms & References \\
\hline TLR4 & Human Mo-DCs, & Viral particles \\
& TLR4-transfected HEK293 cells & \\
TLR3 & Human Mo-DCs, Mouse BMMs, & dsRNA \\
& TLR3-transfected HEK293 cells & \\
MDA5 & Mouse MEFs, & dsRNA \\
& MDA5-transfected HeLa cells & \\
TLR7 & THP-1, & ssRNA \\
& Mouse BMMs & \\
NLRP3 & Human PBMCs, & 1. EV-A71 2B protein induces the \\
& Mouse BMDCs, & redistribution of NLRP3 \\
& THP-1, & 2. EV-A71 3D protein interacts with \\
AIM2 & Mono Mac 6 & the LRR domain of NLRP3 \\
TLR9 & SK-N-SH & Not determined \\
& Mouse pDCs, & Host DNA from dying EV-A71-infected cells \\
\hline
\end{tabular}

Human Mo-DCs human monocyte-derived DCs, HEK293 human embryonic kidney 293, MEFs mouse embryonic fibroblasts, THP-1 human monocytic cell lines, $B M M s$ bone marrow-derived macrophages, $P B M C s$ peripheral blood mononuclear cells, BMDCs bone marrow-derived dendritic cells, $S K-N$-SH human neuroblastoma, Mono Mac 6 human monocytic cell line, $p D C s$ plasmacytoid DCs 
production of proinflammatory cytokines via the TLR7$\mathrm{NF}-\mathrm{KB}$ axis in several cell types, including human monocytic THP-1 cells, mouse bone marrow-derived macrophages (BMMs), and TLR7-expressed HEK293T cells [46]. Further, endosomal adaptor HRS has been shown to play a regulatory role in the assembly of TLR7 complex at endosomes during EV-A71 infection, leading to protection against EV-A71 infection [46]. Another study showed that the treatment of a TLR7 agonist GS-9620 significantly reduces EV-A71 replication in a mouse model [59]. EV-A71 and Coxsackievirus A16 replication are increased in human bronchial epithelial (16HBE) cells via induction of autophagy, which in turn mediates the degradation of endosomes and the TLR7 complex [60]. Of note, a recent study indicated that the allele $C$ at TLR-7 rs3853839 locus has strongly correlated the severity of HFMD caused by EV71 infection [61]. Given the importance of TLR7 signaling in pDCs for type I IFN-mediated antiviral responses, further studies are warranted to investigate the importance of TLR7 in protecting against EV-A71 infection in vivo.

Similar to TLR7, endosomal TLR9 is also highly expressed in pDCs and detects microbial CpG DNA to trigger the MyD88-IKK $\alpha$ pathway to IFN- $\alpha$ production. In addition, TLR9 recognizes DAMPs such as tumorderived mitochondrial DNA, IgG-chromatin complexes and HMGB1 [62]. A recent study using TLR9-deficient mice demonstrated that TLR9 deficiency leads to increased susceptibility to EV-A71 infection in mice [51]. The cytokine profiles of the brain from TLR9-deficient mice after EV-A71 infection exhibit decreased type-I IFN production but the increased production of several cytokines, including IFN- $\gamma$, IL- 6 , IL- $1 \beta$, MIP- $1 \alpha$, MCP- 1 and IP-10 [51]. It is plausible that the protective role of TLR9 in EV-A71 infection is due to TLR9-mediated recognition of endogenous host DNA from dying EV-A71infected cells to induce type I IFN-mediated antiviral responses.

In addition to detecting lipopolysaccharide (LPS) from Gram-negative bacterial infection., TLR4 is also shown to detect several viral proteins [63], such as VSV-G [64], Ebola virus GP [65], influenza HA [66], respiratory syncytial virus fusion protein [67], and dengue virus NS1 protein $[68,69]$. Recent work showed that ectopic expression of TLR4 or TLR4 plus MD2 in HEK293 cells enables the detection of EV-A71 virus-like particles to induce the production of IL-8 [40]. EV-A71 virus-like particles were further shown to induce TLR4-mediated expression of surface markers (like CD80, CD86, CD83, CD40, CD54, and HLA-DR) and production of cytokines (IL-12 p70, IL-12 p40, and IL-10) in human monocytederived DCs [40]. It will be interesting to further explore whether TLR4 is critical for defending against EV-A71 infection in vivo.

\section{A2, EV-A71 viral proteins target the toll-like receptor pathways}

EV-A71, like other viruses, has utilized multiple ways to subvert the host antiviral responses to successfully establish infection. Having discussed the above findings that several TLRs are involved in regulating antiviral responses to EV71 infection, here we also discuss the actions of EVA71 on counteracting the TLR pathways. First, EV-A71 infection results in the reduction of the TLR3 protein level in human neuroblastoma SK-N-SH cells and TLR3transfected HEK293 cells [41]. EV-A71 2A protease is responsible for the cleavage of TLR3 [41]. Further studies are required to determine the mechanistic mechanism of 2A-mediated cleavage of TLR3 in a direct or an indirect manner. Another study showed that EV-A71 infection leads to the selective reduction of Trif adaptor in HeLa and RD cell lines [70]. Further, 3C protease binds and cleaves Trif adaptor to inhibit TLR3 signaling to type I IFN induction, and the Q312- S313 amino acids on Trif are critical for $3 \mathrm{C}$-mediated cleavage [70]. In contrast, the degradation of Trif by EV-A71 3C protease is not occurred in a human colon cancer cell line HT-29 [43, 70]. These data suggest that $3 \mathrm{C}$-mediated cleavage of Trif might be cell context-dependent. EV-A71 3C protease is also shown to target IRF7, a key transcriptional factor for type I IFN activation, at the Q189-S190 site [71].

NF- $\mathrm{kB}$ is a family of transcriptional factors linking PRRs and cytokine receptors (like IL-1 and TNF- $\alpha$ ) to inflammatory responses. Several lines of evidence reveal the interplays between the NF-kB pathway and EV-A71 viral proteins. $3 \mathrm{C}$ protease is shown to block the NF- $\mathrm{kB}$ pathway to proinflammatory cytokine production by targeting the TAK1/TAB1/TAB2/TAB3 complex [72]. EV-A71 2C targets IKK $\beta$ and $\mathrm{p} 65$ to suppress NF- $\mathrm{KB}$ activation [73-75]. In addition to viral factors, EV-A71 infection also induces the expression of host microRNA miR-146a, which in turn downregulates the expression of TRAF6 and IRAK1 involved in TLR signaling to type I IFN induction [76]. Interestingly, depletion of miR-146a in mice by the genetic knockout or specific antagomiR approach restores the expression of IRAK1 and TRAF6, leading to increased IFN $\beta$ production, inhibition of EV-A71 replication and the improved survival rate [76]. The intervention of the TLR pathways by EV-A71 infection described above is illustrated in Fig. 1 and Table 2.

\section{B1, interplays between EV-A71 and the RIG-I-like receptor pathways}

The RLR family consists of three members, including RIG-I, MDA5, and LGP2. Both RIG-I and MDA5 are shown to serve as cytosolic RNA sensors for detecting RNA virus infection while LGP2 function still remains controversial $[85,86]$. MDA5 recognizes long dsRNA or viral RNA lacking 2'-O-methylation at their 5' cap, 
Table 2 EV-A71 viral proteins target PRRs and innate immune regulators

\begin{tabular}{|c|c|c|}
\hline Targeted PRRs and innate immune regulators & Viral factor-mediated mechanisms & References \\
\hline TLR3 & 2A downregulates TLR3 & [41] \\
\hline TRIF & 3C cleaves TRIF at Q312- S313 & {$[43,70]$} \\
\hline RIG-I & $\begin{array}{l}\text { 1. } 3 C \text { targets RIG-I } \\
\text { 2. } 3 C \text { degrades RIG-I }\end{array}$ & $\begin{array}{l}{[77]} \\
{[78]}\end{array}$ \\
\hline MDA5 & $\begin{array}{l}\text { 1. } 2 \text { A degrades MDA5 } \\
\text { 2. Host caspase cleaves MDA5 } \\
\text { 3. } 3 D \text { interacts with the MDA5 CARD region }\end{array}$ & $\begin{array}{l}{[78]} \\
{[44]} \\
{[79]}\end{array}$ \\
\hline MAVS & 2A cleaves MAVS at Gly209, Gly251, and Gly265 & {$[43,80]$} \\
\hline NLRP3 & $\begin{array}{l}\text { 1. 2A cleaves NLRP3 at Q225-G226 } \\
\text { 2. 3C cleaves NLRP3 G493-L494 }\end{array}$ & [48] \\
\hline GSMD & 3C cleaves GSDMD at Q193-G194 & [81] \\
\hline TRAF6/IRAK1 & Host miR-146a downregulates TRAF6/IRAK1 & [76] \\
\hline TAB2/TAK1/TAB1/TAB3 & $\begin{array}{l}\text { 3C cleaves TAB2 at Q113-S114, TAK1 at Q360-S361, } \\
\text { TAB1 at Q414-G415 and Q451-S452, and TAB3 at } \\
\text { Q173-G174 and Q343-G344 }\end{array}$ & [72] \\
\hline IKKß/p65 & $2 C$ targets $1 \mathrm{KK} \beta$ and p65 & {$[73,74]$} \\
\hline IRF7 & 3C cleaves IRF7 at Q189-S190 & [71] \\
\hline IRF9 & 3C cleaves IRF9 & [82] \\
\hline IFNAR1 & 2A downregulates IFNAR1 & [83] \\
\hline ZAP & 3C cleaves ZAP at Q369 -G370 & [84] \\
\hline
\end{tabular}

whereas RIG-I recognizes short dsRNA or viral RNA species containing $5^{\prime}$ triphosphates or $5^{\prime}$ diphosphates [86-89]. Upon RNA ligand binding, RIG-I and MDA5 recruit a mitochondrial adaptor MAVS to activate TRAF3- and TRAF6-mediated downstream pathways for activation of IFN- $\beta$ and inflammatory cytokines, respectively [86]. RIG-I and MDA5 play differential roles in detecting several RNA viruses [86, 90]. RIG-I is responsible for sensing RNA viruses like influenza viruses, VSV, and Japanese encephalitis virus. MDA5 is critical for the recognition of picornaviruses such as encephalomyocarditis virus (EMCV). Some viruses like dengue virus and West Nile virus are recognized by both RIG-I and MDA5 [85, 91]. We discuss recent findings with respect to the interactions between EV-A71 and the RLR pathways (Fig. 1 and Table 1).

A previous study demonstrated that transfection of EV-A71-derived RNA, but not EV-A71 infection, induces phosphorylation of an IFN- $\beta$ transcriptional factor IRF3 in HeLa cells [44]. Further, MDA5 knockdown impairs IRF3 phosphorylation and the activation of the IFN- $\beta$ mRNA in HeLa cells upon EV-A71-derived RNA transfection [44]. In addition, ectopic expression of MDA5 or RIG-I enhances the activation of the IFN- $\beta$ mRNA and IRF3 phosphorylation upon EV-A71 infection [44]. Another study revealed that mouse embryonic fibroblasts deficient in MDA5 or MAVS are impaired in the activation of the IFN- $\beta$ promoter upon EV-A71 viral RNA transfection [45]. However, a study using the reconstitution approach showed that HEK293 cells enable to recognize EV-A71 infection to activate type I IFNs only after ectopic expression of TLR3 but not MDA5 or RIG-I [41]. These findings suggest that MDA5 is able to detect EV-A71 viral RNA and might be involved in the detection of EV-A71 infection in a cell type-dependent way. It is possible that the $5^{\prime}$-end of viral RNAs of picornaviruses are covalently conjugated to VPg protein, and thus interfere RIG-I-mediated RNA sensing [92]. In addition, a report indicated that arrestin domain-containing 4 (ARRDC4), a regulator of G-protein-coupled receptors, interacts with MDA5 to facilitate MDA5 ubiquitination and activation to produce proinflammatory cytokines during EV-A71 infection [93]. A genetic association study noted that a polymorphism of MDA5 (rs1990760) is associated with the severity of EV71 infection in children [94]. The in vivo role of MDA5 in EV-A71 infection remains to be further explored.

\section{B2, EV-A71 viral proteins target the RIG-I-like receptor pathways}

Several studies have shown the molecular mechanisms by which EV-A71 viral proteins target the RLR pathways during EV-A71 infection. A previous study revealed that EVA71 viral protein 1 is co-localized with mitochondria and then induces mitochondrial abnormalities, and $2 \mathrm{~A}$ protease cleaves MAVS at the Gly209, Gly251, and Gly265 residues to suppress type I IFN activation [80]. Degradation of MAVS after EV-A71 infection has been found in HeLa, RD and HT-29 cells $[43,80]$. Feng et al. first showed that EVA71 infection causes the cleavage of RIG-I, MDA5, and MAVS, and recombinant mengoviruses carrying EV-A71 
2A also cleave these RLR molecules [78]. Also, Kuo et al. reported that EV-A71 infection induces the cleavage of endogenous MDA5 in HeLa cells and this MDA5 cleavage relies on the caspase activity from host cells [44]. Yet, more studies are needed to understand the underlying mechanism by which EV-A71 induces the cleavage of MDA5 in host cells by $2 \mathrm{~A}$ protease or an indirect strategy. In addition to $2 \mathrm{~A}$ protease, EV-A71 $3 \mathrm{C}$ protease has also been shown to target the RIG-I pathway. Lei et al. reported that EV-A71 3C protease interacts with RIG-I to suppress Type I IFN activation during EV-A71 infection [77]. The infection of EV-A71 or mengoviruses carrying EV-A71 $3 \mathrm{C}$ protease leads to the cleavage of RIG-I [78]. Interestingly, other enteroviruses, like poliovirus and Coxsackievirus B3 (CVB3), also employed similar strategies to target MDA5 and MAVS by their 2A proteases and to target RIG-I by their $3 \mathrm{C}$ proteases [78], suggesting that enteroviruses may use the common mechanisms to subvert the RLR pathways. Another study reported that EV-A71 3D polymerase interacts with MDA5 to disrupt the engagement of MDA5, leading to the downregulation of MDA5 signaling [79]. Together, the interplays between EV-A71 and the RLR pathways are concisely summarized in Fig. 1 and Table 2.

\section{C1, interplays between EV-A71 and Inflammasomes}

Several NLRs function to form cytosolic inflammasomes to regulate innate immune responses to pathogen infection, tissue damage or metabolic stress $[95,96]$. Among inflammasomes, NLRP3 inflammasome responds to a wide variety of PAMPs and DAMPs, and thus it has been under extensive investigations [96]. NLRP3 inflammasome activation requires two signals. The first signal is to activate the gene expression of pro-IL- $1 \beta$, pro-IL18 , and NLRP3 via the PRR-NF-kB pathways. The second signal is to trigger the complex formation of the NLRP3 inflammasome by NLRP3 ligands, such as ATP, monosodium urate (MSU), pore-forming toxins, pathogen infection, and ultraviolet radiation [96]. Upon ligand stimulation, NLRP3 oligomerizes to recruit ASC and procaspase-1to form a large complex, then resulting in the activation of e caspase- 1 via auto-cleavage [96]. Consequently, activated caspase- 1 cleaves pro-IL- $1 \beta$ or proIL-18 to IL-1 $\beta$ or IL-18 for cytokine secretion [96]. Recent evidence indicated that gasdermin D (GSDMD) is another effector downstream of activated caspase-1, and the cleaved N-terminal portion of GSDMD can trigger pyroptosis and IL-1 $\beta$ secretion via its pore-forming activity [97-99]. Interactions between EV-A71 and inflammasomes have been demonstrated by recent work and briefly shown in Fig. 2 and Table 1.

Several studies showed that NLRP3 inflammasome activation occurs upon picornavirus infection, including EMCV, Rhinovirus, Poliovirus, CVB3, and EV-A71 [47, 100, 101]. Notably, mice deficient in inflammasome mediators, including NLRP3, ASC, Caspase-1 and IL-18, exhibited increased susceptibility to EV-A71 infection [48, 102]. Further evidence indicated that upon EV-A71 infection, NLRP3 inflammasome mediates the production of IL- $1 \beta$ from human monocytic cell lines (THP-1 and Mono Mac 6), human peripheral blood mononuclear cells (PBMCs), and mouse bone marrowderived DCs [48]. One study noticed that EV-A71 3D protein, an RNA-dependent RNA polymerase (RdRp), interacts with the LRR domain of NLRP3 to facilitate the assembly of the inflammasome complex [49]. EV-A71 2B protein was found to induce the redistribution of NLRP3 to the perinuclear region and was co-localized with this redistributed NLRP3 [47]. It is likely that EV-A71 employs multiple mechanisms to engage with the NLRP3 inflammasome.

AIM2 is a cytosolic DNA sensor to detect cytosolic DNA from DNA viruses and other pathogens, and then recruits ASC and procaspase-1to form the inflammasome to trigger IL-1 maturation and pyroptosis [103]. A recent study indicated that AIM2 is highly expressed in the CNS tissues of human EV-A71 encephalomyelitis patients [50]. AIM2 gene expression is up-regulated by the transfection of EV-A71 RNA in SK-N-SH cells [50]. Silencing of AIM2 in SK-N-SH cells impaired the activation of IL-1 and increased viral replication upon EV-A71 infection [50]. The underlying mechanism of how EVA71 activates the AIM2 inflammasome and the in vivo role of AIM2 during EV-A71 infection remains to be further explored.

\section{C2, EV-A71 viral proteins target the NLRP3 inflammasome} EV-A71 develops strategies to subvert inflammasome activation (Fig. 2 and Table 2). EV-A71 2A and 3C proteases were shown to cleave NLRP3 protein at the Q225-G226 pair or the G493-L494 pair respectively to suppress NLRP3 inflammasome activation [48]. Additionally, EVA71 3C protease has also been shown to cleave GSDMD at the Q193-G194 pair to generate a shorter N-terminal GSDMD fragment (1-193 a.a.), leading to the inhibition of pyroptosis to facilitate EV-A71 replication [81].

\section{D1, interplays between EV-A71 and the IFN-ISG axis}

Three types of IFNs exist in the mammalian immune system and play diverse roles in regulating innate and adaptive immunity. Among them, type I IFNs are major cytokines driving antiviral defense at the early stage of viral infection. The signals through type I IFN receptor (IFNAR) to induce expression of over 300 IFNstimulated genes (ISGs), which play diverse roles in interfering viral replication in host cells at different steps $[32,33,104]$. Previous studies showed that treatment of type I IFNs on mice and mammalian cells confers antiviral immunity against EV71 infection [105, 106]. Studies using immunodeficient mouse models indicated that 


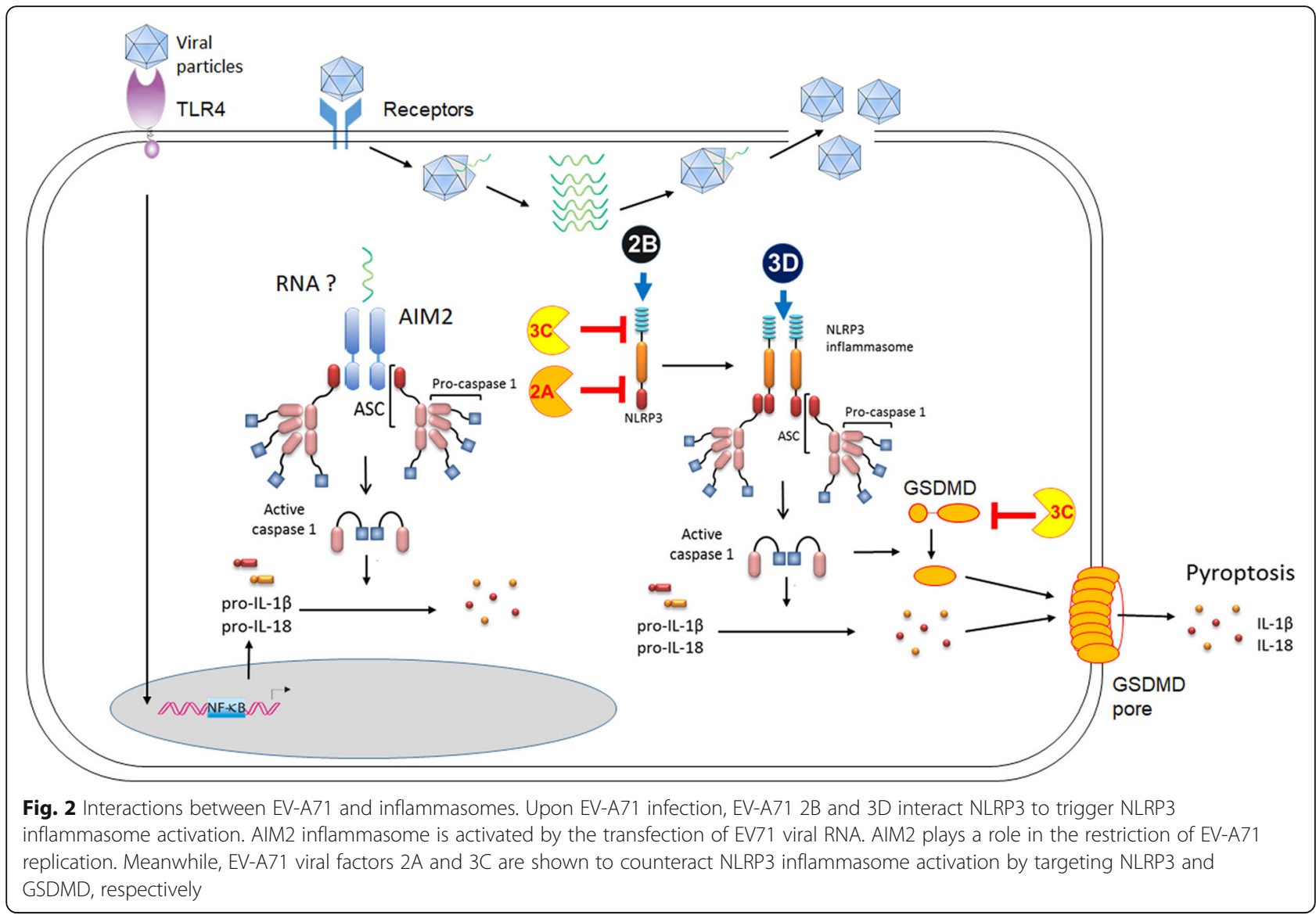

mice deficient in type I and/or type II IFN signaling become highly susceptible to EV-A71 infection [107-110]. Type III IFNs have been shown to play an important role in mucosal epithelial tissues to protect from viral attacks [111]. The natural route of EV-A71 infection is mainly through the gastrointestinal tract. Notably, a recent study indicated that EV-A71 infects human intestinal epithelium to produce type III IFNs (IFN- $\lambda 2 / 3$ ), leading to the restriction of EV-A71 infection [112]. Also, EV71 was shown to be more sensitive to the treatment of IFN $-\lambda 3$ than IFN- $\beta$ [112]. It is conceivable that three types of IFNs may play their roles in distinct cell types to regulate immune responses to EV-A71 infection.

\section{D2, EV-A71 viral proteins target the IFN-ISG axis}

Recent work also revealed the strategies of EV-A71 to antagonize the IFN-ISG axis. Lu et al. found that EV71 attenuates type I IFN signaling via its $2 \mathrm{~A}$ protease to decrease the protein level of interferon receptor 1 (IFNAR1) [83]. EV-A71 3C protease was shown to cleave a transcriptional factor IRF9, which cooperates with STAT2 to mediate ISG expression [82]. A recent study showed that one of ISGs called Zinc-finger antiviral protein (ZAP) exhibits the ability to restrict EV-
A71 replication, and EV-A71 3C protease cleaves ZAP at the Q369-G370 pair to diminish ZAP-mediated effect on EV-A71 replication [84]. Taken together, the interactions between EV-A71 and the IFN-ISG axis are illustrated in Fig. 3 and Table 2.

\section{Concluding remarks}

Considerable progress has been made in understanding the complex interplays between EV-A71 and the innate immune system. Studies using cell lines or mouse models reveal that the mammalian innate immune system may employ multiple PRRs, including TLRs, RLRs, and inflammasomes, to sense the presence of EV-A71 to trigger innate immune responses in different cell types. EV-A71 has evolved multiple ways to subvert these PRR pathways and the IFN-ISG axis to promote viral propagation in host cells. Remarkably, the interactions between EV-A71 and some PRR pathways display a cell type-dependent effect. Further studies using primary cells, organoids, or conditional knockout mouse models may provide insightful knowledge toward understanding the importance of a given PRR pathway in EV-A71 infection. Of interest, insights gained from these studies could be potentially translated into clinic applications in 


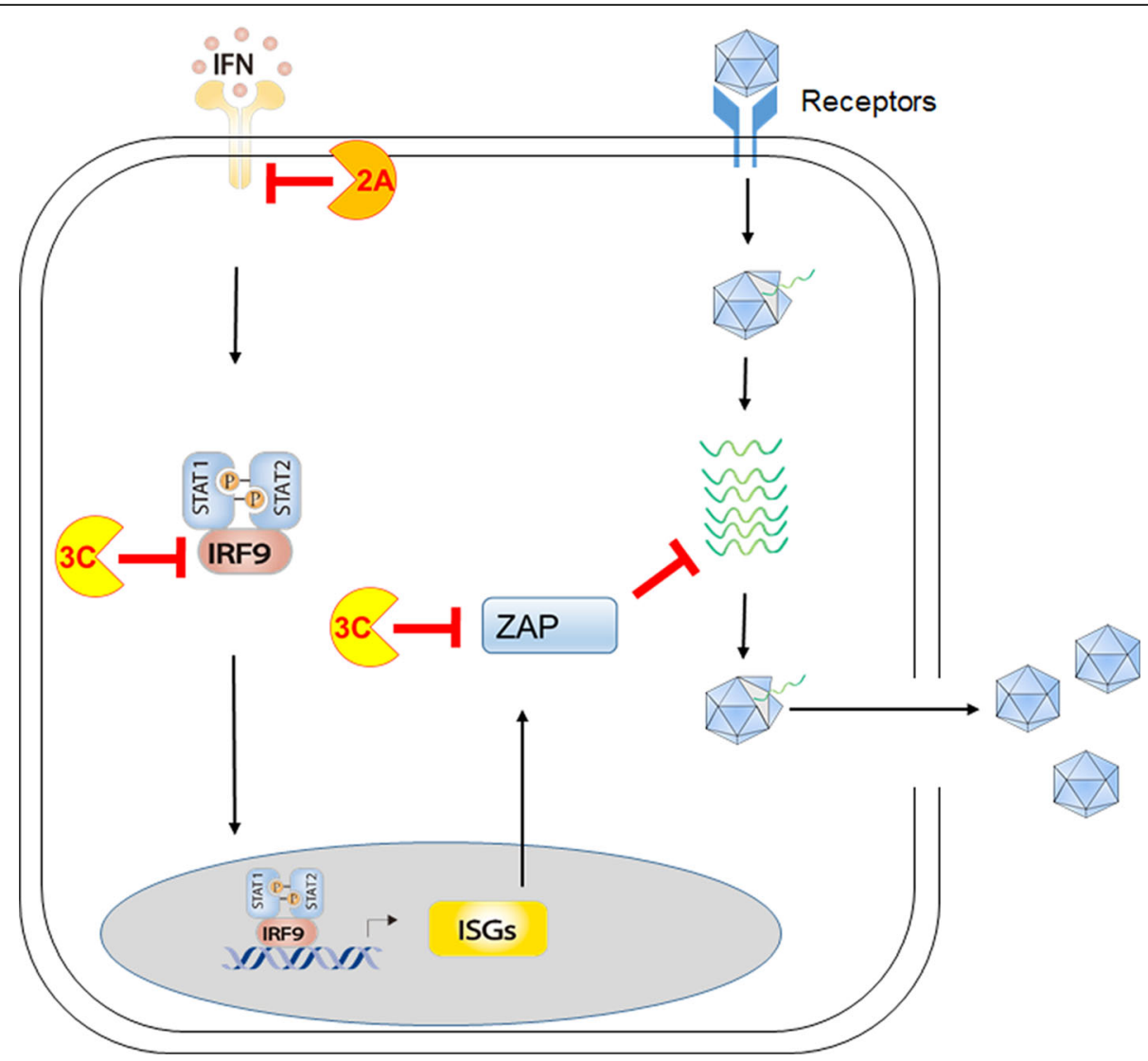

Fig. 3 Interactions between EV-A71 and the type I IFN- signaling pathway. Upon cytokine engagement, type I IFN receptor (IFNAR) triggers the JAK-STAT pathway, leading to the activation of hundreds of IFN-stimulated genes (ISGs) to mount antiviral immunity. EV-A71 $2 \mathrm{~A}$ is shown to target IFNAR and IRF9 to curtail IFNR signaling to ISG induction. EV-A71 3C is shown to target one of ISGs called ZAP, which functions to inhibit viral replication.

the future. For instance, TLR9 ligand CpG has been used as an adjuvant for EV71 mucosal vaccine development [113]. NLRP3 ligand aluminum hydroxide has been included as an adjuvant for inactivated EV71 vaccine in phase III of a clinical trial [10]. In addition, antiviral drugs targeting EV-A71 factors, including protease inhibitors, 3D polymerase inhibitors, and 2C ATPase inhibitors, have been under development [114].

When we have gained certain knowledge about the interplays between EV-A71 and the innate immune system, however, several critical issues remain to be further explored. First, one of the major challenges in this field is lacking suitable mouse models to study EV-A71 infection through the oral-intestinal route. Future development of such models is critical to elucidate the unique operations of mucosal immunity during EV-A71 infection. Also, it will be more insightful to study the roles of tissue-specific innate immune cells in EV-A71 infection, such as microglia in the central nerve system, intestineassociated dendritic cells, macrophages, and innate lymphoid cells. Another critical issue is related to age- dependent immunity, which may affect the outcomes of EV71 infection $[115,116]$. Further studies are needed to determine whether and how the subtle differences of early innate immunity in infants and adults may affect downstream host immune responses to EV-A71 infection. Lastly, it is imperative to translate knowledge gained from studying these critical issues toward the development of EV-A71 vaccines and antiviral therapies.

\section{Abbreviations}

CAV16: Coxsackievirus A16; CVB: Coxsackievirus B; dsRNA: double-stranded RNA; EMCV: Encephalomeningitis virus; EV-A71: Enterovirus A71;

HEK293: Human embryonic kidney 293; HFMD: Hand, foot and mouth disease; IFN: Interferon; ISGs: IFN-stimulated genes; PSGL-1: P-selectin glycoprotein ligand-1; RD: Rhabdomyosarcoma; RLRs: RIG-I-like receptors; SCARB: Scavenger receptor B2; ssRNA: single-stranded RNA; TLR: Toll-like receptor; iNKT: invariant natural killer T; ZAP: Zinc-finger antiviral protein; IVIG: Intravenous immunoglobulin; ADE: Antibody-dependent enhancement; PRRs: Pattern-recognition receptors; TBK-1: TANK-binding kinase 1; ISRE: Interferon-stimulated response element; pDCs: plasmacytoid DCs; VSV: Vesicular stomatitis virus; BMMs: Bone marrow-derived macrophages; HRS: Hepatocyte growth factor-regulated tyrosine kinase substrate; PBMCs: Peripheral blood mononuclear cells; DAMPs: Damage-associated molecular patterns; mtDNA: mitochondrial DNA; HT-29: Human intestinal 
epithelial cells; ARRDC4: Arrestin domain-containing 4; MSU: Monosodium urate; GSDMD: Gasdermin D; IFNAR: IFN receptor

\section{Acknowledgments}

This work was supported in part by intramural funds from the Center of Infectious Disease and.

Signaling Research, and from Allergy \& Clinical Immunology Research Center, National Cheng.

Kung University.

\section{Authors' contributions}

K-RC and PL wrote the manuscript. K-RC and PL read and approved the final manuscript.

\section{Funding}

This work was supported by the Ministry of Science and Technology (1072320-B-006 -027 -MY3) and Academia Sinica (AS-TP-106-L11).

\section{Availability of data and materials}

Not applicable.

\section{Ethics approval and consent to participate}

Not applicable.

\section{Consent for publication}

Not applicable.

\section{Competing interests}

The authors declare that they have no competing interests.

\section{Author details}

${ }^{1}$ Department of Microbiology and Immunology, College of Medicine, National Cheng Kung Univeristy, Tainan, Taiwan. ${ }^{2}$ Institute of Basic Medical Sciences, College of Medicine, National Cheng Kung Universiy, Tainan, Taiwan. ${ }^{3}$ Department of Medical Laboratory Science and Biotechnology, College of Medicine, National Cheng Kung University, Tainan, Taiwan.

\section{Received: 2 July 2019 Accepted: 19 November 2019}

Published online: 02 December 2019

\section{References}

1. Mandary MB, Poh CL. Changes in the EV-A71 Genome through Recombination and Spontaneous Mutations: Impact on Virulence. Viruses. 2018;10(6):320

2. Schmidt $\mathrm{NJ}$, Lennette $\mathrm{EH}, \mathrm{Ho} H \mathrm{H}$. An apparently new enterovirus isolated from patients with disease of the central nervous system. J Infect Dis. 1974; 129(3):304-9.

3. Wang SM, Lei HY, Liu CC. Cytokine immunopathogenesis of enterovirus 71 brain stem encephalitis. Clin Dev Immunol. 2012;2012:876241.

4. Wang SM. Milrinone in Enterovirus 71 brain stem encephalitis. Front Pharmacol. 2016:7:82.

5. Solomon T, Lewthwaite P, Perera D, Cardosa MJ, McMinn P, Ooi MH. Virology, epidemiology, pathogenesis, and control of enterovirus 71. Lancet Infect Dis. 2010;10(11):778-90.

6. Chang YK, Chen KH, Chen KT. Hand, foot and mouth disease and herpangina caused by enterovirus A71 infections: a review of enterovirus A71 molecular epidemiology, pathogenesis, and current vaccine development. Rev Inst Med Trop Sao Paulo. 2018:60:e70.

7. Li R, Liu L, Mo Z, Wang X, Xia J, Liang Z, Zhang Y, Li Y, Mao Q, Wang J, Jiang $L$, Dong $C$, Che $Y$, Huang $T$, Jiang $Z$, Xie Z, Wang L, Liao $Y$, Liang $Y$, Nong Y, Liu J, Zhao H, Na R, Guo L, Pu J, Yang E, Sun L, Cui P, Shi H, Wang J, Li Q. An inactivated enterovirus 71 vaccine in healthy children. N Engl J Med. 2014;370(9):829-37.

8. McMinn PC. Enterovirus vaccines for an emerging cause of brain-stem encephalitis. N Engl J Med. 2014;370(9):792-4.

9. Zhu F, Xu W, Xia J, Liang Z, Liu Y, Zhang X, Tan X, Wang L, Mao Q, Wu J, Hu Y, Ji T, Song L, Liang Q, Zhang B, Gao Q, Li J, Wang S, Hu Y, Gu S, Zhang J, Yao G, Gu J, Wang X, Zhou Y, Chen C, Zhang M, Cao M, Wang J, Wang H, Wang N. Efficacy, safety, and immunogenicity of an enterovirus 71 vaccine in China. N Engl J Med. 2014;370(9):818-28.
10. Zhu FC, Meng FY, Li JX, Li XL, Mao QY, Tao H, Zhang YT, Yao X, Chu K, Chen $\mathrm{QH}$, Hu YM, Wu X, Liu P, Zhu LY, Gao F, Jin H, Chen YJ, Dong YY, Liang YC, Shi NM, Ge HM, Liu L, Chen SG, Ai X, Zhang ZY, Ji YG, Luo FJ, Chen XQ, Zhang Y, Zhu LW, Liang ZL, Shen XL. Efficacy, safety, and immunology of an inactivated alum-adjuvant enterovirus 71 vaccine in children in China: a multicentre, randomised, double-blind, placebo-controlled, phase 3 trial. Lancet. 2013:381(9882):2024-32.

11. Huang LM, Chiu CH, Chiu NC, Lin CY, Li MT, Kuo TY, Weng YJ, Hsieh EF, Tai IC. Immunogenicity, safety, cross-reaction, and immune persistence of an inactivated enterovirus A71 vaccine in children aged from two months to 11 years in Taiwan. Vaccine. 2019;37(13):1827-35.

12. Cheng A, Fung CP, Liu CC, Lin YT, Tsai HY, Chang SC, Chou AH, Chang JY, Jiang $\mathrm{RH}$, Hsieh YC, Su IJ, Chong PC, Hsieh SM. A phase I, randomized, open-label study to evaluate the safety and immunogenicity of an enterovirus 71 vaccine. Vaccine. 2013;31(20):2471-6.

13. Wang SM, Lei HY, Huang MC, Su LY, Lin HC, Yu CK, Wang JL, Liu CC. Modulation of cytokine production by intravenous immunoglobulin in patients with enterovirus 71-associated brainstem encephalitis. J Clin Virol. 2006:37(1):47-52.

14. Wang SM, Chen IC, Su LY, Huang KJ, Lei HY, Liu CC. Enterovirus 71 infection of monocytes with antibody-dependent enhancement. Clin Vaccine Immunol. 2010;17(10):1517-23.

15. Han JF, Cao RY, Deng YQ, Tian X, Jiang T, Qin ED, Qin CF. Antibody dependent enhancement infection of enterovirus 71 in vitro and in vivo. Virol J. 2011:8:106.

16. Cao RY, Dong DY, Liu RJ, Han JF, Wang GC, Zhao H, Li XF, Deng YQ, Zhu SY, Wang XY, Lin F, Zhang FJ, Chen W, Qin ED, Qin CF. Human IgG subclasses against enterovirus type 71: neutralization versus antibody dependent enhancement of infection. PLoS One. 2013;8(5):e64024

17. Nishimura $Y$, Shimojima M, Tano Y, Miyamura T, Wakita T, Shimizu H. Human P-selectin glycoprotein ligand-1 is a functional receptor for enterovirus 71. Nat Med. 2009;15(7):794-7.

18. Yamayoshi S, Yamashita Y, Li J, Hanagata N, Minowa T, Takemura T, Koike S. Scavenger receptor B2 is a cellular receptor for enterovirus 71. Nat Med. 2009;15(7):798-801.

19. Yang $B$, Chuang $H$, Yang KD. Sialylated glycans as receptor and inhibitor of enterovirus 71 infection to DLD-1 intestinal cells. Virol J. 2009;6:141.

20. Su PY, Wang YF, Huang SW, Lo YC, Wang YH, Wu SR, Shieh DB, Chen SH, Wang JR, Lai MD, Chang CF. Cell surface nucleolin facilitates enterovirus 71 binding and infection. J Virol. 2015:89(8):4527-38.

21. Tan CW, Poh CL, Sam IC, Chan YF. Enterovirus 71 uses cell surface heparan sulfate glycosaminoglycan as an attachment receptor. J Virol. 2013;87(1): 611-20.

22. Yeung ML, Jia L, Yip CCY, Chan JFW, Teng JLL, Chan KH, Cai JP, Zhang C, Zhang AJ, Wong WM, Kok KH, Lau SKP, Woo PCY, Lo JYC, Jin DY, Shih SR, Yuen KY. Human tryptophanyl-tRNA synthetase is an IFN-gamma-inducible entry factor for Enterovirus. J Clin Invest. 2018;128(11):5163-77.

23. Yuan J, Shen L, Wu J, Zou X, Gu J, Chen J, Mao L. Enterovirus A71 proteins: structure and function. Front Microbiol. 2018;9:286.

24. Takeuchi O, Akira S. Pattern recognition receptors and inflammation. Cell. 2010:140(6):805-20.

25. Holm CK, Paludan SR, Fitzgerald KA. DNA recognition in immunity and disease. Curr Opin Immunol. 2013;25(1):13-8.

26. Broz P, Monack DM. Newly described pattern recognition receptors team up against intracellular pathogens. Nat Rev Immunol. 2013;13(8):551-65.

27. Zhang Z, Yuan B, Bao M, Lu N, Kim T, Liu YJ. The helicase DDX41 senses intracellular DNA mediated by the adaptor STING in dendritic cells. Nat Immunol. 2011;12(10):959-65.

28. Unterholzner L, Keating SE, Baran M, Horan KA, Jensen SB, Sharma S, Sirois CM, Jin T, Latz E, Xiao TS, Fitzgerald KA, Paludan SR, Bowie AG. IFI16 is an innate immune sensor for intracellular DNA. Nat Immunol. 2010;11(11):997-1004.

29. Paludan SR, Bowie AG. Immune sensing of DNA. Immunity. 2013;38(5): 870-80

30. Aoshi T, Koyama S, Kobiyama K, Akira S, Ishii KJ. Innate and adaptive immune responses to viral infection and vaccination. Curr Opin Virol. 2011; 1(4):226-32

31. Sadler AJ, Williams BR. Interferon-inducible antiviral effectors. Nat Rev Immunol. 2008;8(7):559-68.

32. Kawai T, Akira S. Toll-like receptors and their crosstalk with other innate receptors in infection and immunity. Immunity. 2011;34(5):637-50. 
33. Chow J, Franz KM, Kagan JC. PRRs are watching you: Localization of innate sensing and signaling regulators. Virology. 2015;479-480:104-9.

34. McNab F, Mayer-Barber K, Sher A, Wack A, O'Garra A. Type I interferons in infectious disease. Nat Rev Immunol. 2015;15(2):87-103.

35. Lazear HM, Schoggins JW, Diamond MS. Shared and distinct functions of type I and type III Interferons. Immunity. 2019;50(4):907-23.

36. Garcia-Sastre A. Ten Strategies of interferon evasion by viruses. Cell Host Microbe. 2017;22(2):176-84

37. Bowie AG, Unterholzner L. Viral evasion and subversion of patternrecognition receptor signalling. Nat Rev Immunol. 2008;8(12):911-22.

38. O'Neill LA, Bowie AG. The family of five: TIR-domain-containing adaptors in toll-like receptor signalling. Nat Rev Immunol. 2007;7(5):353-64.

39. Seya T, Matsumoto M, Ebihara T, Oshiumi H. Functional evolution of the TICAM-1 pathway for extrinsic RNA sensing. Immunol Rev. 2009; 227(1):44-53.

40. Lin YL, Hu YC, Liang CC, Lin SY, Liang YC, Yuan HP, Chiang BL. Enterovirus71 virus-like particles induce the activation and maturation of human monocyte-derived dendritic cells through TLR4 signaling. PLoS One. 2014; 9(10):e0111496.

41. Chen KR, Yu CK, Kung SH, Chen SH, Chang CF, Ho TC, Lee YP, Chang HC, Huang LY, Lo SY, Chang JC, Ling P. Toll-Like Receptor 3 Is Involved in Detection of Enterovirus A71 Infection and Targeted by Viral 2A Protease. Viruses. 2018;10(12).

42. Zhu K, Yang J, Luo K, Yang C, Zhang N, Xu R, Chen J, Jin M, Xu B, Guo N, Wang J, Chen Z, Cui Y, Zhao H, Wang Y, Deng C, Bai L, Ge B, Qin CF, Shen $H$, Yang CF, Leng $Q$. TLR3 signaling in macrophages is indispensable for the protective immunity of invariant natural killer T cells against enterovirus 71 infection. PLoS Pathog. 2015;11(1):e1004613.

43. Wang C, Ji L, Yuan X, Jin Y, Cardona CJ, Xing Z. Differential regulation of TLR signaling on the induction of antiviral Interferons in human intestinal epithelial cells infected with Enterovirus 71. PLoS One. 2016;11(3):e0152177.

44. Kuo RL, Kao LT, Lin SJ, Wang RY, Shih SR. MDA5 plays a crucial role in enterovirus 71 RNA-mediated IRF3 activation. PLoS One. 2013;8(5):e63431.

45. Feng Q, Hato SV, Langereis MA, Zoll J, Virgen-Slane R, Peisley A, Hur S, Semler BL, van Rij RP, van Kuppeveld FJ. MDA5 detects the doublestranded RNA replicative form in picornavirus-infected cells. Cell Rep. 2012;2(5):1187-96.

46. Luo Z, Ge M, Chen J, Geng Q, Tian M, Qiao Z, Bai L, Zhang Q, Zhu C, Xiong Y, Wu K, Liu F, Liu Y, Wu J. HRS plays an important role for TLR7 signaling to orchestrate inflammation and innate immunity upon EV71 infection. PLoS Pathog. 2017;13(8):e1006585

47. Ito M, Yanagi $Y$, Ichinohe $T$. Encephalomyocarditis virus viroporin $2 B$ activates NLRP3 inflammasome. PLoS Pathog. 2012;8(8):e1002857.

48. Wang H, Lei X, Xiao X, Yang C, Lu W, Huang Z, Leng Q, Jin Q, He B, Meng G, Wang J. Reciprocal regulation between Enterovirus 71 and the NLRP3 Inflammasome. Cell Rep. 2015;12(1):42-8.

49. Wang W, Xiao F, Wan P, Pan P, Zhang Y, Liu F, Wu K, Liu Y, Wu J. EV71 3D protein binds with NLRP3 and enhances the assembly of Inflammasome complex. PLoS Pathog. 2017;13(1):e1006123.

50. Yogarajah T, Ong KC, Perera D, Wong KT. AIM2 Inflammasome-mediated Pyroptosis in Enterovirus A71-infected neuronal cells restricts viral replication. Sci Rep. 2017;7(1):5845.

51. Hsiao HB, Chou AH, Lin SI, Chen IH, Lien SP, Liu CC, Chong P, Liu SJ. Toll-like receptor 9-mediated protection of enterovirus 71 infection in mice is due to the release of danger-associated molecular patterns. J Virol. 2014;88(20): $11658-70$.

52. Lester SN, Li K. Toll-like receptors in antiviral innate immunity. J Mol Biol. 2014;426(6):1246-64

53. Abe Y, Fujii K, Nagata N, Takeuchi O, Akira S, Oshiumi H, Matsumoto M, Seya T, Koike $\mathrm{S}$. The toll-like receptor 3-mediated antiviral response is important for protection against poliovirus infection in poliovirus receptor transgenic mice. J Virol. 2012;86(1):185-94.

54. Yang J, Yang C, Guo N, Zhu K, Luo K, Zhang N, Zhao H, Cui Y, Chen L, Wang H, Gu J, Ge B, Qin CF, Leng Q. Type I Interferons triggered through the toll-like receptor 3-TRIF pathway control Coxsackievirus A16 infection in Young mice. J Virol. 2015;89(21):10860-7.

55. Yu CK, Chen CC, Chen CL, Wang JR, Liu CC, Yan JJ, Su IJ. Neutralizing antibody provided protection against enterovirus type 71 lethal challenge in neonatal mice. J Biomed Sci. 2000;7(6):523-8.

56. Li YP, Li M, Jia XL, Deng HL, Wang WJ, Wu FP, Wang J, Dang SS. Association of gene polymorphisms of pattern-recognition receptor signaling pathway with the risk and severity of hand, foot, and mouth disease caused by enterovirus 71 in Chinese Han population. J Med Virol. 2018;90(4):692-8.

57. He H, Liu S, Liu PP, Li QB, Tan YX, Guo Y, Li F, Wang YY, Liu YD, Yang CQ, Chen ZB. Association of Toll-like receptor 3 gene polymorphism with the severity of enterovirus 71 infection in Chinese children. Arch Virol. 2017; 162(6):1717-23.

58. Kawai T, Akira S. The role of pattern-recognition receptors in innate immunity: update on toll-like receptors. Nat Immunol. 2010;11(5):373-84.

59. Zhang $H$, Wang $X$, Wang $Y$, Pei $X$, Wang C, Niu Y, Xu P, Peng Y. Substituted 3-benzylcoumarins 13 and 14 suppress enterovirus $A 71$ replication by impairing viral 2A(pro) dependent IRES-driven translation. Antivir Res. 2018; 160:10-16.

60. Song J, Hu Y, Li J, Zheng H, Wang J, Guo L, Shi H, Liu L. Suppression of the toll-like receptor 7-dependent type I interferon production pathway by autophagy resulting from enterovirus 71 and coxsackievirus A16 infections facilitates their replication. Arch Virol. 2018;163(1):135-44

61. Zhang Y, Suo X, Zhang Y. Association of IL-13, S100B, and TLR-7 gene polymorphisms with Enterovirus 71 infection in hand, foot, and mouth disease in China. Genet Test Mol Biomarkers. 2019;23(3):188-96.

62. Patidar A, Selvaraj S, Sarode A, Chauhan P, Chattopadhyay D, Saha B. DAMPTLR-cytokine axis dictates the fate of tumor. Cytokine. 2018;104:114-23.

63. Olejnik J, Hume AJ, Muhlberger E. Toll-like receptor 4 in acute viral infection: too much of a good thing. PLoS Pathog. 2018;14(12):e1007390.

64. Georgel P, Jiang Z, Kunz S, Janssen E, Mols J, Hoebe K, Bahram S, Oldstone MB, Beutler B. Vesicular stomatitis virus glycoprotein $G$ activates a specific antiviral toll-like receptor 4-dependent pathway. Virology. 2007;362(2):304-13.

65. Okumura A, Pitha PM, Yoshimura A, Harty RN. Interaction between Ebola virus glycoprotein and host toll-like receptor 4 leads to induction of proinflammatory cytokines and SOCS1. J Virol. 2010;84(1):27-33.

66. Zhang S, Gu D, Ouyang X, Xie W. Proinflammatory effects of the hemagglutinin protein of the avian influenza a (H7N9) virus and microRNAmediated homeostasis response in THP1 cells. Mol Med Rep. 2015:12(4):6241-6.

67. Rallabhandi P, Phillips RL, Boukhvalova MS, Pletneva LM, Shirey KA, Gioannini TL, Weiss JP, Chow JC, Hawkins LD, Vogel SN, Blanco JC. Respiratory syncytial virus fusion protein-induced toll-like receptor 4 (TLR4) signaling is inhibited by the TLR4 antagonists Rhodobacter sphaeroides lipopolysaccharide and eritoran (E5564) and requires direct interaction with MD-2. MBio. 2012;3(4)

68. Modhiran N, Watterson D, Blumenthal A, Baxter AG, Young PR, Stacey KJ. Dengue virus NS1 protein activates immune cells via TLR4 but not TLR2 or TLR6. Immunol Cell Biol. 2017:95(5):491-5.

69. Modhiran N, Watterson D, Muller DA, Panetta AK, Sester DP, Liu L, Hume DA, Stacey KJ, Young PR. Dengue virus NS1 protein activates cells via Tolllike receptor 4 and disrupts endothelial cell monolayer integrity. Sci Transl Med. 2015:7(304):304ra142.

70. Lei $X$, Sun Z, Liu X, Jin Q, He B, Wang J. Cleavage of the adaptor protein TRIF by enterovirus $713 \mathrm{C}$ inhibits antiviral responses mediated by toll-like receptor 3. J Virol. 2011;85(17):8811-8.

71. Lei X, Xiao X, Xue Q, Jin Q, He B, Wang J. Cleavage of interferon regulatory factor 7 by enterovirus 71 3C suppresses cellular responses. J Virol. 2013; 87(3):1690-8.

72. Lei X, Han N, Xiao X, Jin Q, He B, Wang J. Enterovirus 713 inhibits cytokine expression through cleavage of the TAK1/TAB1/TAB2/TAB3 complex. J Virol. 2014;88(17):9830-41

73. Du $H$, Yin $P$, Yang $X$, Zhang $L$, Jin Q, Zhu G. Enterovirus $712 C$ protein inhibits NF-kappaB activation by binding to RelA(p65). Sci Rep. 2015;5:14302.

74. Zheng Z, Li H, Zhang Z, Meng J, Mao D, Bai B, Lu B, Mao P, Hu Q, Wang H. Enterovirus $712 \mathrm{C}$ protein inhibits TNF-alpha-mediated activation of NFkappaB by suppressing IkappaB kinase beta phosphorylation. J Immunol. 2011;187(5):2202-12

75. Li Q, Zheng Z, Liu Y, Zhang Z, Liu Q, Meng J, Ke X, Hu Q, Wang H. 2 C proteins of enteroviruses suppress IKKbeta phosphorylation by recruiting protein phosphatase 1. J Virol. 2016;90(10):5141-51.

76. Ho BC, Yu IS, Lu LF, Rudensky A, Chen HY, Tsai CW, Chang YL, Wu CT, Chang LY, Shih SR, Lin SW, Lee CN, Yang PC, Yu SL. Inhibition of miR-146a prevents enterovirus-induced death by restoring the production of type I interferon. Nat Commun. 2014;5:3344.

77. Lei $X$, Liu X, Ma Y, Sun Z, Yang Y, Jin Q, He B, Wang J. The $3 C$ protein of enterovirus 71 inhibits retinoid acid-inducible gene I-mediated interferon 
regulatory factor 3 activation and type I interferon responses. J Virol. 2010; 84(16):8051-61.

78. Feng Q, Langereis MA, Lork M, Nguyen M, Hato SV, Lanke K, Emdad L, Bhoopathi P, Fisher PB, Lloyd RE, van Kuppeveld FJ. Enterovirus 2Apro targets MDA5 and MAVS in infected cells. J Virol. 2014;88(6):3369-78.

79. Kuo RL, Chen CJ, Wang RYL, Huang HI, Lin YH, Tam EH, Tu WJ, Wu SE, Shih SR. Role of enteroviral RNA-dependent RNA polymerase in regulation of MDA5-mediated interferon-beta activation. J Virol. 2019:93(10):132-19.

80. Wang B, Xi X, Lei X, Zhang X, Cui S, Wang J, Jin Q, Zhao Z. Enterovirus 71 protease 2Apro targets MAVS to inhibit anti-viral type I interferon responses. PLoS Pathog. 2013;9(3):e1003231.

81. Lei X, Zhang Z, Xiao X, Qi J, He B, Wang J. Enterovirus 71 Inhibits Pyroptosis through Cleavage of Gasdermin D. J Virol. 2017;91(18).

82. Hung HC, Wang HC, Shih SR, Teng IF, Tseng CP, Hsu JT. Synergistic inhibition of enterovirus 71 replication by interferon and rupintrivir. J Infect Dis. 2011;203(12):1784-90.

83. Lu J, Yi L, Zhao J, Yu J, Chen Y, Lin MC, Kung HF, He ML. Enterovirus 71 disrupts interferon signaling by reducing the level of interferon receptor 1. J Virol. 2012;86(7):3767-76.

84. Xie L, Lu B, Zheng Z, Miao Y, Liu Y, Zhang Y, Zheng C, Ke X, Hu Q, Wang H. The $3 C$ protease of enterovirus $A 71$ counteracts the activity of host zincfinger antiviral protein (ZAP). J Gen Virol. 2018;99(1):73-85.

85. Loo YM, Gale M Jr. Immune signaling by RIG-Ilike receptors. Immunity. 2011;34(5):680-92.

86. Goubau D, Schlee M, Deddouche S, Pruiijssers AJ, Zillinger T, Goldeck M, Schuberth C, Van der Veen AG, Fujimura T, Rehwinkel J, Iskarpatyoti JA, Barchet W, Ludwig J, Dermody TS, Hartmann G. And Reis e Sousa C. antiviral immunity via RIG-I-mediated recognition of RNA bearing 5'diphosphates. Nature. 2014;514(7522):372-5.

87. Zust R, Cervantes-Barragan L, Habjan M, Maier R, Neuman BW, Ziebuhr J, Szretter K, Baker SC, Barchet W, Diamond MS, Siddell SG, Ludewig B, Thiel V. Ribose 2'-O-methylation provides a molecular signature for the distinction of self and non-self mRNA dependent on the RNA sensor Mda5. Nat Immunol. 2011;12(2):137-43.

88. Hornung V, Ellegast J, Kim S, Brzozka K, Jung A, Kato H, Poeck H, Akira S, Conzelmann KK, Schlee M, Endres S, Hartmann G. 5'-triphosphate RNA is the ligand for RIG-I. Science. 2006;314(5801):994-7.

89. Kato H, Takeuchi O, Mikamo-Satoh E, Hirai R, Kawai T, Matsushita K, Hiiragi A, Dermody TS, Fujita T, Akira S. Length-dependent recognition of doublestranded ribonucleic acids by retinoic acid-inducible gene-I and melanoma differentiation-associated gene 5. J Exp Med. 2008;205(7):1601-10

90. Kato H, Takeuchi O, Sato S, Yoneyama M, Yamamoto M, Matsui K, Uematsu S, Jung A, Kawai T, Ishii KJ, Yamaguchi O, Otsu K, Tsujimura T, Koh CS, Reis e Sousa C, Matsuura Y, Fujita T, Akira S. Differential roles of MDA5 and RIG-I helicases in the recognition of RNA viruses. Nature. 2006;441(7089):101-5.

91. Schoggins JW, Rice CM. Interferon-stimulated genes and their antiviral effector functions. Curr Opin Virol. 2011;1(6):519-25.

92. Liu Y, Olagnier D, Lin R. Host and viral modulation of RIG-I-mediated antiviral immunity. Front Immunol. 2016;7:662.

93. Meng J, Yao Z, He Y, Zhang R, Zhang Y, Yao X, Yang H, Chen L, Zhang Z, Zhang H, Bao X, Hu G, Wu T, Cheng J. ARRDC4 regulates enterovirus 71induced innate immune response by promoting $\mathrm{K} 63$ polyubiquitination of MDA5 through TRIM65. Cell Death Dis. 2017;8(6):e2866.

94. Pang L, Gong X, Liu N, Xie G, Gao W, Kong G, Li X, Zhang J, Jin Y, Duan Z. A polymorphism in melanoma differentiation-associated gene 5 may be a risk factor for enterovirus 71 infection. Clin Microbiol Infect. 2014;20(10):0711-7.

95. Lamkanfi M, Dixit VM. Mechanisms and functions of inflammasomes. Cell. 2014;157(5):1013-22.

96. Guo H, Callaway JB, Ting JP. Inflammasomes: mechanism of action, role in disease, and therapeutics. Nat Med. 2015;21(7):677-87.

97. Shi J, Zhao Y, Wang K, Shi X, Wang Y, Huang H, Zhuang Y, Cai T, Wang F, Shao F. Cleavage of GSDMD by inflammatory caspases determines pyroptotic cell death. Nature. 2015;526(7575):660-5.

98. Liu X, Zhang Z, Ruan J, Pan Y, Magupalli VG, Wu H, Lieberman J. Inflammasome-activated gasdermin D causes pyroptosis by forming membrane pores. Nature. 2016;535(7610):153-8.

99. Ding J, Wang K, Liu W, She Y, Sun Q, Shi J, Sun H, Wang DC, Shao F. Poreforming activity and structural autoinhibition of the gasdermin family. Nature. 2016;535(7610):111-6.
100. Wang C, Fung G, Deng H, Jagdeo J, Mohamud Y, Xue YC, Jan E, Hirota JA, Luo H. NLRP3 deficiency exacerbates enterovirus infection in mice. FASEB J. 2019;33(1):942-52.

101. Triantafilou K, Kar S, van Kuppeveld FJ, Triantafilou M. Rhinovirus-induced calcium flux triggers NLRP3 and NLRC5 activation in bronchial cells. Am J Respir Cell Mol Biol. 2013;49(6):923-34.

102. Li Z, Wang H, Chen Y, Niu J, Guo Q, Leng Q, Huang Z, Deng Z, Meng G. Interleukin-18 protects mice from Enterovirus 71 infection. Cytokine. 2017; 96:132-7.

103. Lugrin J, Martinon F. The AIM2 inflammasome: sensor of pathogens and cellular perturbations. Immunol Rev. 2018;281(1):99-114.

104. Schneider WM, Chevillotte MD, Rice CM. Interferon-stimulated genes: a complex web of host defenses. Annu Rev Immunol. 2014;32:513-45.

105. Liu ML, Lee YP, Wang YF, Lei HY, Liu CC, Wang SM, Su IJ, Wang JR, Yeh TM, Chen SH, Yu CK. Type I interferons protect mice against enterovirus 71 infection. J Gen Virol. 2005;86(Pt 12):3263-9.

106. Yi L, He Y, Chen Y, Kung HF, He ML. Potent inhibition of human enterovirus 71 replication by type I interferon subtypes. Antivir Ther. 2011;16(1):51-8.

107. Khong WX, Yan B, Yeo H, Tan EL, Lee JJ, Ng JK, Chow VT, Alonso S. A nonmouse-adapted enterovirus 71 (EV71) strain exhibits neurotropism, causing neurological manifestations in a novel mouse model of EV71 infection. J Virol. 2012;86(4):2121-31.

108. Liao CC, Liou AT, Chang YS, Wu SY, Chang CS, Lee CK, Kung JT, Tu PH, Yu YY, Lin CY, Lin JS, Shih C. Immunodeficient mouse models with different disease profiles by in vivo infection with the same clinical isolate of enterovirus 71. J Virol. 2014;88(21):12485-99.

109. Caine EA, Partidos CD, Santangelo JD, Osorio JE. Adaptation of enterovirus 71 to adult interferon deficient mice. PLoS One. 2013;8(3):e59501.

110. Wang LC, Chen SO, Chang SP, Lee YP, Yu CK, Chen CL, Tseng PC, Hsieh CY, Chen SH, Lin CF. Enterovirus 71 proteins $2 \mathrm{~A}$ and $3 \mathrm{D}$ antagonize the antiviral activity of gamma interferon via signaling attenuation. J Virol. 2015;89(14): 7028-37.

111. Wack A, Terczynska-Dyla E, Hartmann R. Guarding the frontiers: the biology of type III interferons. Nat Immunol. 2015;16(8):802-9.

112. Good C, Wells Al, Coyne CB. Type III interferon signaling restricts enterovirus 71 infection of goblet cells. Sci Adv. 2019;5(3):eaau4255.

113. Lin YL, Chow YH, Huang LM, Hsieh SM, Cheng PY, Hu KC, Chiang BL. A CpG-adjuvanted intranasal enterovirus 71 vaccine elicits mucosal and systemic immune responses and protects human SCARB2-transgenic mice against lethal challenge. Sci Rep. 2018;8(1):10713.

114. Bauer L, Lyoo H, van der Schaar HM, Strating JR, van Kuppeveld FJ. Directacting antivirals and host-targeting strategies to combat enterovirus infections. Curr Opin Virol. 2017;24:1-8.

115. Kollmann TR, Levy O, Montgomery RR, Goriely S. Innate immune function by toll-like receptors: distinct responses in newborns and the elderly. Immunity. 2012;37(5):771-83.

116. Gantt S, Yao L, Kollmann TR, Casper C, Zhang J, Self SG. Implications of age-dependent immune responses to Enterovirus 71 infection for disease pathogenesis and vaccine design. J Pediatric Infect Dis Soc. 2013;2(2):162-70.

\section{Publisher's Note}

Springer Nature remains neutral with regard to jurisdictional claims in published maps and institutional affiliations.

\section{Ready to submit your research? Choose BMC and benefit from:}

- fast, convenient online submission

- thorough peer review by experienced researchers in your field

- rapid publication on acceptance

- support for research data, including large and complex data types

- gold Open Access which fosters wider collaboration and increased citations

- maximum visibility for your research: over $100 \mathrm{M}$ website views per year

At BMC, research is always in progress.

Learn more biomedcentral.com/submission 